\title{
Correction to: Pediatric procedural sedation and analgesia in the emergency department: surveying the current European practice
}

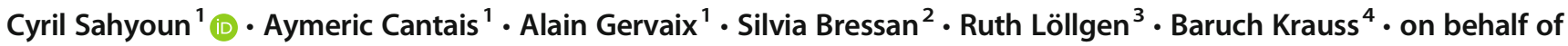 \\ the Pediatric Emergency Medicine Comfort and Analgesia Research in Europe (PemCARE) group of the Research in \\ European Pediatric Emergency Medicine (REPEM) network
}

(C) The Author(s) 2021

\section{Correction to: European Journal of Pediatrics https://doi.org/10.1007/s00431-021-03930-6}

In the Acknowledgement section of the original published version of the above article, the complete list of the Country Lead Research Coordinators of PemCARE group of the REPEM network were not mentioned thus the Acknowledgments has been corrected as follows:

Acknowledgments The authors wish to thank each country lead research coordinator and each of the survey participants who gave their time to diffuse or complete the survey.

\section{Country Lead Research Coordinators of PemCARE} group of the REPEM network

Annick de Jaeger, Ghent University Hospital, Belgium Marianne Sjølin Frederiksen, pediatric emergency department, Copenhagen University Hospital, Herlev, Denmark Gérard Chéron, Necker Enfants Malades Hospital, Université de Paris, France

The online version of the original article can be found at https://doi.org/ 10.1007/s00431-021-03930-6
Katharina Röher, University Medical Center HamburgEppendorf, Hamburg, Germany

Florian Hoffmann, Dr. von Hauner Children's Hospital, Ludwig-Maximilians-University, Munich, Germany

László Fodor, Fejér County Szent György University Teaching Hospital, Székesfehérvár, Hungary

Idanna Sforzi, Anna Meyer Children's Hospital, Florence, Italy

Itai Shavit, Rambam Health Care Campus, Israel

Zanda Pucuka, BKUS Children Clinical University Hospital, Latvia

Vytenis Masilionis, The Hospital of Lithuanian University of Health Sciences, Klauno Klinikos, Kaunas, Lithuania

Ruth Farrugia, Mater Dei Hospital, Msida, Malta

Dorine Borensztajn, Erasmus MC-Sophia Children's Hospital, Rotterdam, The Netherlands.

Ana Garrido Centro Hospitalar Tamega e Sousa, Portugal Diana Moldovan, Emergency Department, Tirgu Mures Emergency Clinical County Hospital, Targu Mures, Romania

Baruch Krauss

baruch.krauss@childrens.harvard.edu

1 Division of Pediatric Emergency Medicine, Children's Hospital of Geneva, Geneva University Hospitals, Rue Gabrielle-Perret-Gentil, 4, 1205 Geneva, Switzerland

2 Department of Women's and Children's Health, University of Padova, Padova, Italy

3 Pediatric Emergency Department, Inselspital, University Hospital, University of Bern, Bern, Switzerland

4 Division of Emergency Medicine, Boston Children's Hospital, Harvard Medical School, Boston, MA, USA 
Maria-Concepcion Miguez Navarro, Hospital General Universitario Gregorio Marañón, Madrid, España

Ioannis Orfanos, Department of Pediatrics, Skane University Hospital, Lund University, Sweden

Anil Er, Dokuz Eylul University School of Medicine, Izmir, Turkey

Murat Duman, Dokuz Eylul University School of Medicine, Izmir, Turkey

The original article has been corrected.
Open Access This article is licensed under a Creative Commons Attribution 4.0 International License, which permits use, sharing, adaptation, distribution and reproduction in any medium or format, as long as you give appropriate credit to the original author(s) and the source, provide a link to the Creative Commons licence, and indicate if changes were made. The images or other third party material in this article are included in the article's Creative Commons licence, unless indicated otherwise in a credit line to the material. If material is not included in the article's Creative Commons licence and your intended use is not permitted by statutory regulation or exceeds the permitted use, you will need to obtain permission directly from the copyright holder. To view a copy of this licence, visit http://creativecommons.org/licenses/by/4.0/.

Publisher's note Springer Nature remains neutral with regard to jurisdictional claims in published maps and institutional affiliations. 